\title{
In memoriam Pierre-Henri Prélot
}

\section{Françoise Curtit et Francis Messner}

\section{OpenEdition}

\section{Journals}

Édition électronique

URL : https://journals.openedition.org/rdr/1420

DOI : $10.4000 /$ rdr 1420

ISSN : 2534-7462

\section{Éditeur}

Presses universitaires de Strasbourg

\section{Édition imprimée}

Date de publication : 6 mai 2021

Pagination : 5

ISBN : $979-10-344-0089-8$

ISSN : 2493-8637

\section{Référence électronique}

Françoise Curtit et Francis Messner, «In memoriam Pierre-Henri Prélot », Revue du droit des religions [En ligne], 11 | 2021, mis en ligne le 06 mai 2021, consulté le 03 mai 2022. URL : http:// journals.openedition.org/rdr/1420; DOI : https://doi.org/10.4000/rdr.1420

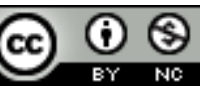

La revue du droit des religions est mise à disposition selon les termes de la Creative Commons Attribution - Pas d'Utilisation Commerciale 4.0 International - CC BY-NC 4.0. 


\section{In memoriam Pierre-Henri Prélot}

Toute l'équipe de la Revue du droit des religions tient à saluer la mémoire de Pierre-Henri Prélot décédé le 19 février dernier. Membre actif du comité de rédaction dès la création de la revue, il avait dirigé deux dossiers thématiques et participé à plusieurs numéros. Nous sommes heureux de publier dans celui-ci encore une de ses contributions si stimulantes.

Il avait initié avec d'autres les travaux en droit des religions en France et la discipline lui doit beaucoup. Nous garderons le souvenir d'un collègue engagé et brillant, toujours prêt à porter et à accompagner des dossiers complexes avec enthousiasme et une incomparable ténacité. Le long chemin parsemé d'embûches de la rédaction du Traité de droit français des religions a illustré ses qualités académiques augmentées d'une rare capacité de travailler en équipe, de respecter et d'entendre les arguments de tous sans distinction de statut et de hiérarchie. Son expertise était très appréciée à l'université de Strasbourg où il était régulièrement sollicité pour prendre part aux conférences et séminaires organisés depuis 1998 par l'UMR SDRE devenue UMR DRES. Nous restent aussi en mémoire nos nombreuses discussions et ses réparties humoristiques au cours des repas d'après colloques qu'il affectionnait particulièrement. Ses qualités humaines étaient à la hauteur de ses mérites académiques.

Le départ de Pierre-Henri laisse un grand vide, son acuité intellectuelle et son amitié vont évidemment nous manquer. Mais sa marque demeure et gageons qu'elle inspirera de futurs engagements dans le champ du droit des religions. 